\begin{tabular}{|c|c|}
\hline $\begin{array}{l}\text { Postprint } \\
\text { Version }\end{array}$ & 1.0 \\
\hline Journal website & http://pmj.sagepub.com/cgi/pmidlookup?view=long\&pmid=268142 \\
\hline Pubmed link & http://www.ncbi.nlm.nih.gov/pubmed/26814214 \\
\hline DOI & $10.1177 / 0269216315627123$ \\
\hline
\end{tabular}

This is a NIVEL certified Post Print, more info at http://www.nivel.eu

\title{
Differences in palliative care quality between patients with cancer, patients with organ failure and frail patients: A study based on measurements with the Consumer Quality Index Palliative Care for bereaved relatives
}

\author{
JOLIEN M HOFSTEDE ${ }^{1,2}$, NATASJA JH RAIJMAKERS ${ }^{1,2}$, LUCAS S VAN DER HOEK $^{1}$, ANNEKE L \\ FRANCKE ${ }^{1,2,3}$ \\ ${ }^{1}$ Netherlands Institute for Health Services Research (NIVEL), Utrecht, The Netherlands \\ ${ }^{2}$ Palliative Care Expertise Centre, VU University Medical Center, Amsterdam, The \\ Netherlands \\ ${ }^{3}$ Department of Public and Occupational Health, EMGO+ Institute for Health and Care \\ Research, VU University Medical Center, Amsterdam, The Netherlands
}

\begin{abstract}
Background: Palliative care is rooted in the care for incurably ill cancer patients. Yet today there is a recognised need for palliative care for patients with noncancer conditions. However, the often unpredictable illness trajectories and the difficulty in predicting the imminence of death in people with non-cancer conditions may hamper the provision of high-quality palliative care.

Aim: To compare the quality of palliative care provided to patients with cancer, patients with organ failure and frail patients and their relatives.

Design: An existing dataset was analysed, consisting of data collected through the Consumer Quality Index Palliative Care questionnaire for bereaved relatives. Setting/participants: Data were analysed of 456 relatives of deceased patients with cancer, patients with organ failure and frail patients from various care settings in the Netherlands.

Results: Relatives (e.g. partners or children) of deceased patients with organ failure $(n=61)$ were more likely to have negative experiences regarding the expertise of healthcare professionals compared with relatives of patients with cancer $(n=215)$. Relatives of frail patients $(n=180)$ gave a relatively low rating of the general quality of the care in the last week of the patient's life, both as regards the care provided to patients $(\mathrm{p}=0.015)$ and as regards the support to relatives $(p=0.009)$.
\end{abstract}


Conclusion: Compared with the bereaved relatives of patients with cancer, bereaved relatives of patients with organ failure or frailty were more likely to negatively assess the palliative care provided to both the patient and themselves. Improving professionals' expertise in palliative care for people with non-cancer conditions is recommended.

\section{What is already known about the topic?}

- Palliative care needs are present in both patients with cancer and patients with non-cancer conditions.

- The difficulty of predicting the imminence of death in non-cancer patients has been identified as an important barrier to identifying palliative care needs.

\section{What this paper adds?}

- Bereaved relatives of patients with organ failure or frailty are more likely to report negative experiences with the palliative care provided to both the patient and themselves compared with relatives of patients with cancer.

- Bereaved relatives of patients with organ failure are more likely to give a negative assessment of professionals' expertise.

- Bereaved relatives of frail patients give a lower rating of the general quality of palliative care.

\section{Implications for practice, theory or policy}

- More attention should be given to broadening healthcare professionals' expertise in palliative care for people with non-cancer conditions.

- Further research is needed on both patients' perspectives and relatives' perspectives on the quality of palliative care in earlier stages of the illness trajectory.

\section{INTRODUCTION}

Patterns of mortality in the Western world have changed over the past century. Where sudden death, mainly due to infectious diseases, used to be the main cause of death, ${ }^{1}$ nowadays chronic progressive diseases - such as cancer, chronic heart failure, chronic obstructive pulmonary disease (COPD) and dementia - have become frequent causes of death. ${ }^{2}$ With this shift, the need for palliative care has increased. Modern palliative care has its roots in the care for incurably ill cancer patients ${ }^{3}$ and occurs, thereby, more commonly among cancer patients than patients with other diseases. ${ }^{4}$ However, as patients with non-cancer conditions may also experience physical, psychosocial and spiritual problems at the end of life, ${ }^{5}$ palliative care should be targeted to them as well.

Three common illness trajectories can be distinguished in patients potentially in need of palliative care, ${ }^{6 \Downarrow-8}$ as illustrated in Figure 1. The first trajectory consists of a short period of evident decline and a foreseen death; this trajectory is often found in cancer 
patients. The second trajectory is characterised by a pattern of long-term limitations, intermittent serious episodes and remissions, often resulting in a relatively sudden death. This type of illness trajectory is mostly found in patients who die of organnivel system failure, such as COPD or chronic heart failure. The third trajectory shows a more gradual, prolonged dwindling towards death. The frail elderly (e.g. those with dementia or severe stroke) are often faced with this gradual decline in functioning. It is often more difficult to mark the onset of the palliative phase in the latter two groups compared with patients with cancer due to more uncertainty at the outset about how the disease will develop along with the related care needs.

\section{[FIGURE 1]}

This difficulty in predicting the course of illness trajectories and, ultimately, the imminence of death in non-cancer groups has been identified as an important barrier to identifying palliative care needs. ${ }^{9}, 10$ It is, therefore, expected that the quality of palliative care provided to patients with non-cancer conditions will be lower than in cancer patients. Hence, the aim of this article is to gain insight into the quality of palliative care, as perceived by the bereaved relatives, given to patients with cancer, organ failure or frailty. The specific research questions are as follows:

- Does the quality of care provided to patients in the last week of life differ between patients with cancer, organ failure and frailty?

- Does the quality of support provided to relatives in the last week of the patient's life and after the patient's death differ between relatives of patients with cancer, organ failure and frailty?

\section{METHODS}

\section{Description of the data and the population}

The data were obtained in the evaluation study of the Dutch National Quality Improvement Programme for Palliative Care. ${ }^{11}$ This programme (2012-2016) is open to all healthcare providers who aim to improve palliative care. For this article, we used data reported by bereaved relatives regarding the quality of palliative care in the first 2 years (March 2013-June 2014). Only pre-test data were analysed (i.e. data collected before the start of the quality improvement projects). The data concerned different types of care settings: hospitals, hospices, residential elderly care and homecare. The bereaved relatives completed a postal questionnaire: the Consumer Quality Index Palliative Care for bereaved relatives. ${ }^{12}$ The bereaved relatives (e.g. patients' partners or children or other family members) had been the contact person for a patient who had died after a sickbed between 6 weeks and 6 months previously and had been involved in the care of that patient. The healthcare professionals participating in the improvement programme collected the contact details of the bereaved relatives who met the inclusion criteria (e.g. via registration systems within their care organisations, or medical records). In total, 1252 bereaved relatives were 
approached for participation, of which 627 fully completed their questionnaire (main) reasons for dropout were not returning the questionnaire, or they did not meet the inclusion criteria). We only used data relating to patients who had a disease coverddvel in the three groups according to the classification of Lynn and Adamson. ${ }^{6}$ These three groups concerned patients with cancer, organ failure (including COPD, chronic heart failure and kidney failure) and frailty (including dementia, stroke, Parkinson's disease or hip fracture and with age $\geqslant 65$ years $^{8}$ ). Data of bereaved relatives of patients who could be assigned to more than one of the three aforementioned categories were excluded. This resulted in a dataset of 456 bereaved relatives eligible for analysis.

\section{Questionnaire}

The Consumer Quality Index Palliative Care version for bereaved relatives addresses (a) care experiences regarding the care provided to the patient in the last week of life and (b) the support and bereavement care given to the relative. ${ }^{12}$ A total of 30 items are pre-structured and have four answer categories. An example of such an item is as follows: 'Did the healthcare professionals take personal wishes of your relative into account?' (never, sometimes, usually, always). Five structured questions have two possible answer categories ('yes' and 'no'), for example, the item 'Did you feel supported by the healthcare professionals immediately after the death of your relative?'. Furthermore, the questionnaire asks for ratings of the general quality using a scale from 0 (very poor care) to 10 (excellent care). Two open questions regarding wishes for improvement in care for the patient and support for the relative are also included. Additionally, questions about the background characteristics (e.g. sex and age) of both the deceased patient and the relative are included in the questionnaire.

\section{Data analyses}

The Consumer Quality Index Palliative Care consists of six dimensions. ${ }^{12}$ Two dimensions focus on the quality of palliative care provided to patients ('care for the psychosocial/spiritual well-being of the patient' and 'expertise') and four on care provided to the relatives ('autonomy', 'care for the relative's own psychosocial/spiritual well-being', 'attitude to the relatives' and 'information for the relative in the last week before death'). These dimensions were scored as the percentage of respondents having negative experiences, calculated as the average of the percentage of respondents with a negative experience in the individual items included in each dimension. A 'negative experience' was defined as a response of 'never' or 'sometimes' for four-category items and 'no' for two-category items. Answers to the open questions regarding the wishes for improvement in the care provided were categorised independently by two researchers (J.M.H. and N.J.H.R.). Any discrepancies were discussed until consensus was established.

Descriptive statistics (frequencies, percentages and means) were computed for the background characteristics, experiences and wishes for improvement. Differences between groups were calculated using multilevel analysis (for the dimensions), logistic regression (for individual items) and linear regression (for the general quality 
ratings). Differences between groups for items regarding the care provided to patients were corrected for the age and gender of the patient and age and perceived health of the bereaved relative; items regarding care and support provided to relatives were corrected for the age, gender, educational level and perceived health of the bereaved relative. ${ }^{13}$ STATA 13 was used for the statistical analysis.

\section{Ethical approval}

The study protocol of the evaluation of the National Quality Improvement Programme for Palliative Care was approved by the Medical Ethical Committee of the University Medical Center in Leiden, the Netherlands. Bereaved relatives had been informed in a letter about the fact that the data could be used for further analysis. Returning the questionnaire was considered as providing informed consent. We observed the rules of the Dutch Personal Data Protection Act (Wet Bescherming Persoonsgegevens). All personal identifiers were removed or encrypted in the analysis process to safeguard the privacy and anonymity of participants.

\section{RESULTS}

\section{Characteristics of patients and bereaved relatives}

The 456 bereaved relatives in the analysis were mainly female $(65 \%)$ and the majority of these relatives felt they were in good health $(87 \%)$. The characteristics of the relatives are given in Table 1.

\section{[TABLE 1.]}

The majority of the deceased patients were 75 years or older $(68 \%)$, about half were female $(52 \%)$ and most patients died in a facility for residential elderly care $(42 \%)$, at home $(33 \%)$ or in hospital (14\%) (Table 2). Of the total of 456 patients, most $(47 \%)$ had cancer, and $13 \%$ of the patients suffered from organ system failure (heart failure, COPD and/or kidney failure). The patients categorised as 'frail' (39\%) were mainly patients with dementia and/or who had had a stroke.

\section{[TABLE 2]}

\section{Quality of care for patients in the last week of life}

Relatives of patients with organ failure were significantly more likely to have had negative experiences in the dimension 'expertise' compared with the relatives of patients with cancer (odds ratio $(\mathrm{OR})=9.7,95 \%$ confidence interval $(\mathrm{CI})=1.6-$ 57.9). This dimension consists of items about the expertise of the healthcare professionals, the continuity of care delivered by different healthcare professionals and timely help in acute situations. 
The relatives of cancer patients gave an average score of 8.8, standard deviation $(\mathrm{SD})=1.3$ for the care for the patient in the last week of life, while the mean rating in both non-cancer groups was $8.3, \mathrm{SD}=1.6-1.7$. The general quality rating by relatives in the frailty group was significantly lower compared with that of the relatives of cancer patients $(p=0.015)$. Additionally, significantly fewer relatives in the frailty group reported that the patient had access to a spiritual counsellor compared with relatives of patients with cancer $(\mathrm{OR}=5.4,95 \% \mathrm{CI}=1.4-21.7)$ (Table 3$)$.

\section{[TABLE 3]}

\section{Quality of care for the relative}

There were no significant differences between the groups regarding specific items on care and support for the relative in the last week of the patient's life. The general quality rating for the care and support for the relatives of cancer patients in the last week before the patient's death was $8.4, \mathrm{SD}=1.7$. The rating was significantly lower for relatives in the frailty group $(7.9, \mathrm{SD}=1.9, p=0.009)$, but not in the organ failure group $(7.9, \mathrm{SD}=2.1, p=0.137)$. Overall, support for relatives after the patient's death (bereavement care) was rated lower than support during the patient's final week of life $(7.7, \mathrm{SD}=2.2)$, but did not differ significantly between the groups.

Additionally, bereaved relatives were less likely to have had positive experiences with bereavement care: $58 \%$ said that no final conversation or discussion had taken place in which the care and treatment were evaluated and 53\% said that they had not been informed about the possibilities of bereavement care. Significantly, more relatives in the frailty group had less positive experiences with the latter item concerning bereavement care compared with the relatives in the cancer group $(\mathrm{OR}=1.9,95 \% \mathrm{CI}=1.2-2.9)($ Table 4$)$.

\section{[TABLE 4.]}

\section{Wishes for improvement in the care and support to patient and relatives}

A total of 180 relatives (39\%) identified one or more wishes for improvement in response to the open questions in the questionnaire: 246 wishes for improvement were mentioned regarding care for patients and 168 regarding support for the relatives (an individual relative could report more than one wish for improvement). The top three most frequently mentioned areas for improvement are listed in Table 5. The most frequently mentioned area regarding improvement in the care for the patient concerned organisational aspects (referring to irregular visits, different healthcare professionals, limited capacity and/or availability of healthcare professionals). Improvement in the communication by healthcare professionals was the most frequently mentioned area for improvement regarding the support for the relatives themselves. There were only minor differences between the three groups regarding the reported wishes for improvement. 


\section{[TABLE 5. ]}

\section{DISCUSSION}

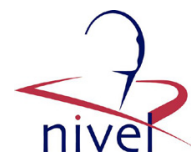

The quality of palliative care differed between patients with cancer and those with organ failure or frailty, as perceived by their bereaved relatives. Bereaved relatives of patients with organ failure were more likely to give a negative assessment of the expertise of healthcare professionals compared with the bereaved relatives of patients with cancer. Even though ratings on the general quality of care were high in all three groups, there was a difference between the groups in the general quality of care. Bereaved relatives of frail patients gave a lower rating to both the care for the patient and for themselves in the last week of the patient's life compared with the relatives of cancer patients. Additionally, frail patients were less likely to have had access to a spiritual counsellor, and their relatives were less likely to have received information about bereavement care.

A noteworthy outcome is that the bereaved relatives of patients with organ failure had a more negative perception of professionals' expertise. The dimension 'expertise' includes items regarding the expertise of healthcare professionals, the continuity of care between professionals and timely help in acute situations. Our finding of more negative experiences with expertise in the organ failure group is in line with previous studies that reported a lack of continuity in care for COPD patients. ${ }^{14}$ Additionally, a lack of specific expertise in non-cancer diseases has earlier been indicated by healthcare professionals in specialist palliative care. ${ }^{15}$ Moreover, healthcare professionals have recently expressed interest in further skills acquisition regarding end-of-life care for patients with heart failure. ${ }^{16}$

\section{Methodological considerations}

Our classification of the three patient groups (cancer, organ failure and frailty) is based on the criteria of Lynn and Adamson ${ }^{6}$ and Lunney et al. ${ }^{8}$ In accordance with the criteria of Lunney et al., we considered a patient as 'frail' when he or she was aged at least 65 years and had at least one medical diagnosis that had led to death. We decided to use the criteria of Lunney et al. because we considered these in accordance with the original illness trajectories described by Lynn and Adamson. ${ }^{6}$ However, there are several options for classifying conditions into a cancer group, organ failure group and frailty group. In taking the approach we did, we deviate from the Golden Standard Framework, ${ }^{17}$ for instance, which defines the frailty group as older persons with multiple comorbidities. Nonetheless, regardless of the criteria used to classify frailty, it will mainly consist of the same type of people: the elderly who died from one of two frequent causes, namely, dementia or a stroke, which also holds for our data. It should be taken into account, though, that any classification into groups in relation to common illness trajectories is a simplification of reality: individual illness trajectories may vary considerably even among patients with the same illness. ${ }^{7}$ 
Another methodological reflection concerns the unequal distribution of groups over care settings. In our study, most patients with cancer had died at home or in a hospice, while most patients with organ failure and frail patients had died in a settingel for residential care of the elderly. We did not statistically adjust for differences in care settings, as we considered care setting as one of the aspects of the quality of care provided. ${ }^{18}$ Still the care setting did not appear to be a decisive factor for the perceived quality of care. For example, when we looked exclusively at the data of relatives of patients who had died at home, the perceived quality of care was still higher in the cancer group than in the other two groups (data not shown).

\section{Implications for practice and further research}

Our results suggest that healthcare professionals should pay more attention to potential palliative care needs in patients with non-cancer conditions. Moreover, improving professionals' expertise in palliative care for patients with organ failure conditions, for example, COPD or heart failure, and the frail elderly is recommended. The implementation and use of recently developed disease-specific recommendations and guidelines ${ }^{19-23}$ should help improve professionals' expertise and, ultimately, the quality of palliative care for non-cancer patients.

This article is based on data of bereaved relatives who were asked to consider their care experiences in the last week of the patient's life and during bereavement care. However, palliative care covers a broader concept than the last week of life and bereavement care, and may start at an early stage of the illness trajectory when lifeprolonging treatments are also still at stake. ${ }^{6} \mathrm{We}$, therefore, recommend more research on the quality of palliative care in earlier stages of the illness trajectory, preferably from the perspectives of both relatives and patients. Data on the quality of palliative care as experienced by patients themselves are currently being collected in the evaluation of the Dutch National Quality Improvement Programme for Palliative Care. $^{11}$

A limitation of our article is that we only compared data from the bereaved relatives of three groups: patients with cancer, patients with organ failure and frail patients. This was a consequence of our decision to link our analysis to the classification of the three illness trajectories of Lynn and Adamson. ${ }^{6}$ Therefore, we did not analyse the data of relatives of patients who had died of progressive neurological disorders, such as amyotrophic lateral sclerosis (ALS) or multiple sclerosis (MS). Clearly, highquality palliative care is also important for patients with these diseases. Therefore, more research is needed to gain insight into the perceived quality of palliative care for these patients, especially as earlier research suggests that these patients have a relatively high risk of receiving inadequate palliative care. ${ }^{24}$ 


\section{CONCLUSION}

The quality of palliative care, measured through the eyes of bereaved relatives, nivel differs between patients with cancer and patients with organ failure or patients with frailty. Relatives of frail patients gave a lower assessment of the general quality of palliative care than the relatives of cancer patients, while relatives of patients with organ failure were more likely to have had a negative experience of the expertise of healthcare professionals. Improving professionals' expertise in delivering palliative care to people with non-cancer conditions may contribute to better care at the end of life.

\section{ACKNOWLEDGMENTS}

The authors would like to thank the bereaved relatives who responded for their valuable contribution.

\section{ARTICLE NOTES}

- Declaration of conflicting interests The author(s) declared no potential conflicts of interest with respect to the research, authorship and/or publication of this article.

- Funding The author(s) received no financial support for the research, authorship and/or publication of this article.

\section{REFERENCES}

1. De Flora S, Quaglia A, Bennicelli C, et al. The epidemiological revolution of the 20th century. FASEB J 2005; 19(8): 892-897.

2. Van der Velden LF, Francke AL, Hingstman L, et al. Dying from cancer or other chronic diseases in the Netherlands: ten-year trends derived from death certificate data. BMC Palliat Care 2009; 8: 4.

3. Clark D. From margins to centre: a review of the history of palliative care in cancer. Lancet Oncol 2007; 8(5): 430-438.

4. Evans N, Pasman HR, Donker GA, et al. End-of-life care in general practice: a cross-sectional, retrospective survey of 'cancer', 'organ failure' and 'old-age/dementia' patients. Palliat Med 2014; 28(7): 965-975.

5. Moens K, Higginson IJ, Harding R, et al. Are there differ- ences in the prevalence of palliative care-related problems in people living with advanced cancer and eight noncancer conditions? A systematic review. J Pain Symptom Manage 2014; 48(4): 660-677.

6. Lynn J and Adamson DM. Living well at the end of life: adapting health care to serious chronic illness in old age. White paper, RAND Health, 2003, https://www.rand.org/ content/dam/rand/pubs/white_papers/2005/WP137.pdf

7. Murray SA, Kendall M, Boyd K, et al. Illness trajectories and palliative care. BMJ 2005; 330(7498): 1007-1011.

8. Lunney JR, Lynn J and Hogan C. Profiles of older medicare decedents. J Am Geriatr Soc 2002; 50(6): 1108-1112.

9. Claessen SJ, Francke AL, Echteld MA, et al. GPs' recogni- tion of death in the foreseeable future and diagnosis of a fatal condition: a national survey. BMC Fam Pract 2013; 14: 104.

10. Oishi $A$ and Murtagh FE. The challenges of uncertainty and interprofessional collaboration in palliative care for non- cancer patients in the community: a systematic 
review of views from patients, carers and health-care professionals. Palliat Med 2014;

28(9): 1081-1098.
11. Raijmakers NJ, Hofstede JM, De Nijs EJ, et al. The effect and process evaluatiqn\$ं $\quad$ e the national quality improvement programme for palliative care: the study protocol. BMC Palliat Care 2014; 13(1): 5.

12. Claessen SJ, Francke AL, Sixma HJ, et al. Measuring rela- tives' perspectives on the quality of palliative care: the Consumer Quality Index Palliative Care. J Pain Symptom Manage 2013; 45(5): 875-884.

13. Fakhoury WK, McCarthy M and Addington-Hall J. Carers' health status: is it associated with their evaluation of the qual- ity of palliative care? Scand J Soc Med 1997; 25(4): 296-301.

14. Janssen DJ and McCormick JR. Palliative care and pulmo- nary rehabilitation. Clin Chest Med 2014; 35(2): 411-421.

15. O'Leary $\mathrm{N}$ and Tiernan $\mathrm{E}$. Survey of specialist palliative care services for noncancer patients in Ireland and perceived barriers. Palliat Med 2008; 22(1): 77-83.

16. Dunlay SM, Foxen JL, Cole T, et al. A survey of clinician attitudes and self-reported practices regarding end-of-life care in heart failure. Palliat Med. Epub ahead of print 8 December 2014. DOI: 10.1177/0269216314556565.

17. Thomas K. The GSF prognostic indicator guidance, 4th ed. The Gold Standards Framework Centre in End of Life Care CIC, http://www.goldstandardsframework.org.uk/ cdcontent/uploads/files/General\%20Files/Prognostic\%20 Indicator\%20Guidance\%20October\%202011.pdf (2011, accessed 2 December 2014).

18. Teno JM, Clarridge BR, Casey V, et al. Family perspectives on end-of-life care at the last place of care. JAMA 2004; 291(1): 88-93.

19. Davidson PM, Macdonald PS, Newton PJ, et al. End stage heart failure patients palliative care in general practice. Aust Fam Physician 2010; 39(12): 916-920.

20. Bellersen L, Knubben A and Van Bommel J. Richtlijn palliatieve zorg bij chronisch hartfalen [Guideline palliative care in chronic heart failure]. Vereniging van Integrale Kankercentra, http://www.oncoline.nl/uploaded/FILES/ Hartfalen/RichtlijnHartfalen20100413\%20(commentaarfase). doc (2010, accessed 10 December 2014) (in Dutch).

21. Long Alliantie Nederland. Richtlijn Palliative Zorg voor mensen met COPD [Guideline palliative care for people with COPD],

http://www.longalliantie.nl/index.php/download_file/view/101/130/ (2011, accessed 10 December 2014) (in Dutch).

22. Van der Steen JT, Radbruch L, Hertogh CM, et al. White paper defining optimal palliative care in older people with dementia: a Delphi study and recommendations from the European Association for Palliative Care. Palliat Med 2014; 28(3): 197-209.

23. National Institute for Health and Clinical Excellence (NICE). Services for people with chronic obstructive pulmonary disease, http://www.nice.org.uk/guidance/cmg43 (2011, accessed 10 December 2014).

24. Maessen M, Veldink JH, Onwuteaka-Philipsen BD, et al. Euthanasia and physicianassisted suicide in amyotrophic lateral sclerosis: a prospective study. J Neurol 2014; 261(10): 1894-1901. 
Hofstede, J.M., Raijmakers, N.J.H., Hoek, L.S. van der, Francke, A.L. Differences in palliative care quality between patients with cancer, patients with organ failure and frail patients: a study based on measurements with the Consumer Quality Index Palliative Care for bereaved relatives.

Palliative Medicine: 2016, 30(8), 780-788

\section{TABLES AND FIGURES}

Figure 1. Illness trajectories.

Source: Lynn and Adamson.6

1) Cancer

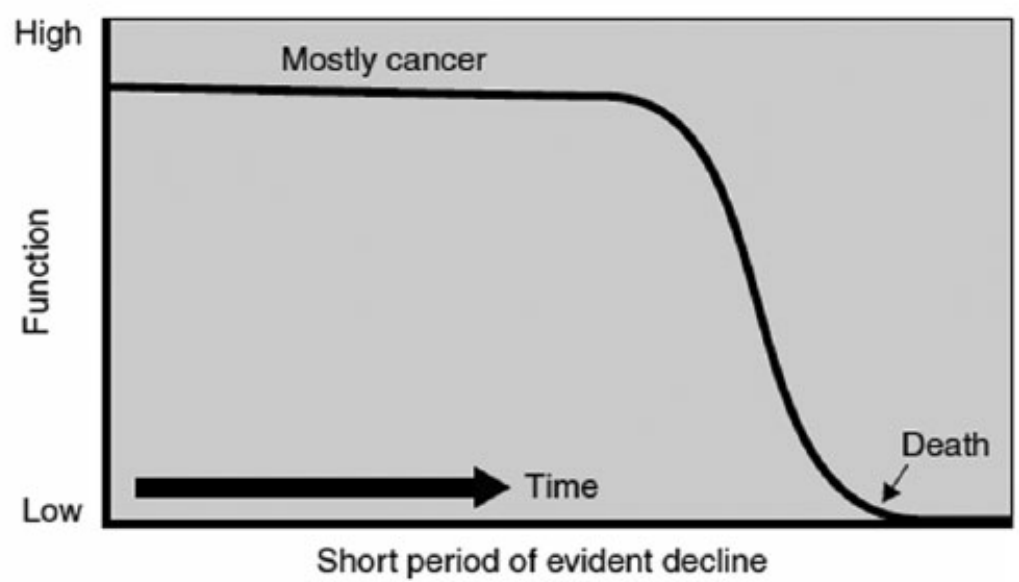

2) Organ failure

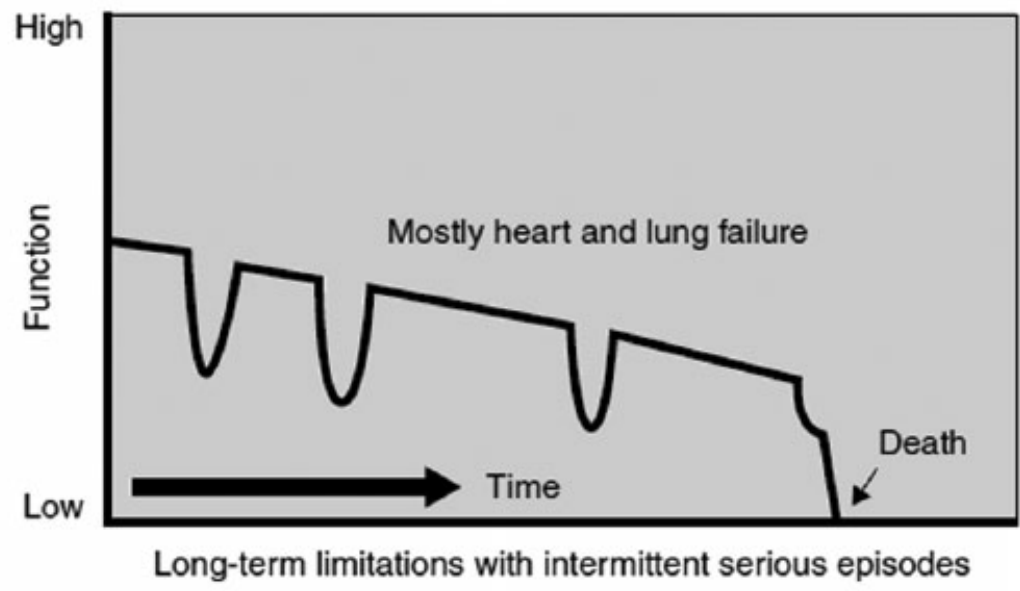

\section{3) Frailty}

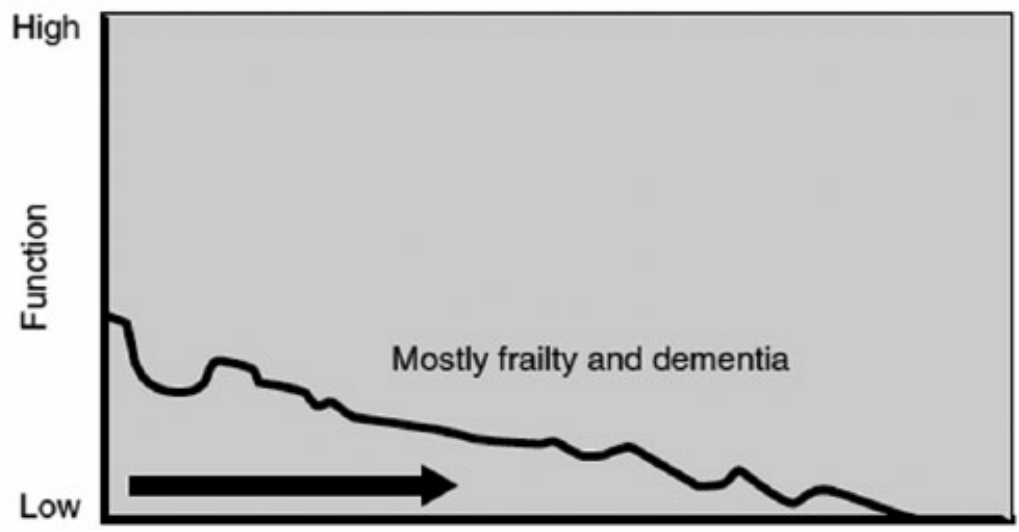


Hofstede, J.M., Raijmakers, N.J.H., Hoek, L.S. van der, Francke, A.L. Differences in palliative care quality between patients with cancer, patients with organ failure and frail patients: a study based on measurements with the Consumer Quality Index Palliative Care for bereaved relatives.

Palliative Medicine: 2016, 30(8), 780-788

Table I. Characteristics of the bereaved relatives.

\begin{tabular}{|c|c|c|c|c|}
\hline & Cancer $(n=215)$ & Organ failure $(n=61)$ & Frailty $(n=180)$ & Total $(n=456)$ \\
\hline & $n(\%)$ & $n(\%)$ & $n(\%)$ & $n(\%)$ \\
\hline \multicolumn{5}{|l|}{ Age (years) } \\
\hline $18-54$ & $67(31)$ & $14(23)$ & $53(30)$ & $134(30)$ \\
\hline $55-74$ & $108(50)$ & $37(6 I)$ & $102(57)$ & $247(54)$ \\
\hline$\geqslant 75$ & 40 (19) & $10(16)$ & $23(13)$ & $73(16)$ \\
\hline \multicolumn{5}{|l|}{ Gender } \\
\hline Male & $79(37)$ & $20(33)$ & $59(33)$ & $158(35)$ \\
\hline Female & $136(63)$ & $41(67)$ & $119(67)$ & $296(65)$ \\
\hline \multicolumn{5}{|l|}{ Relationship with deceased patient } \\
\hline Partner & $139(65)$ & $16(26)$ & $29(16)$ & $184(40)$ \\
\hline Child & $47(22)$ & $38(62)$ & $124(69)$ & $209(46)$ \\
\hline Family other than partner or child & $19(9)$ & $5(8)$ & $19(11)$ & $43(9)$ \\
\hline Other, no family & $9(4)$ & $2(3)$ & $8(4)$ & $19(4)$ \\
\hline \multicolumn{5}{|l|}{ Education } \\
\hline None or primary education & $105(50)$ & $28(48)$ & 67 (39) & $200(45)$ \\
\hline Secondary education & $45(22)$ & $15(26)$ & $49(28)$ & $109(25)$ \\
\hline Higher education & $59(28)$ & $15(26)$ & $58(33)$ & $132(30)$ \\
\hline \multicolumn{5}{|l|}{ Perceived health } \\
\hline Good, very good, excellent & $173(8 \mid)$ & $55(90)$ & $166(92)$ & $394(87)$ \\
\hline Fair, poor & 40 (19) & $6(10)$ & $14(8)$ & $60(13)$ \\
\hline
\end{tabular}

Table 2. Characteristics of deceased patients.

\begin{tabular}{|c|c|c|c|c|}
\hline & Cancer $(n=215)$ & Organ failure $(n=61)$ & Frailty $(n=180)$ & Total $(n=456)$ \\
\hline & $n(\%)$ & $n(\%)$ & $n(\%)$ & $n(\%)$ \\
\hline \multicolumn{5}{|l|}{ Age (years) } \\
\hline $18-54$ & $31(16)$ & I (2) & $0(0)$ & $32(7)$ \\
\hline $55-74$ & $90(45)$ & $7(13)$ & II (6) & $108(25)$ \\
\hline$\geqslant 75$ & $79(40)$ & $47(85)$ & $168(94)$ & $294(68)$ \\
\hline \multicolumn{5}{|l|}{ Gender } \\
\hline Male & $119(55)$ & $33(54)$ & $68(38)$ & $220(48)$ \\
\hline Female & $96(45)$ & $28(46)$ & $112(62)$ & $236(52)$ \\
\hline \multicolumn{5}{|l|}{ Place of death } \\
\hline Home & $113(53)$ & $22(36)$ & $14(8)$ & $149(33)$ \\
\hline Hospital & $34(16)$ & $11(18)$ & $17(10)$ & $62(14)$ \\
\hline Of which PCU & $4(2)$ & $0(0)$ & $2(1)$ & $6(1)$ \\
\hline $\begin{array}{l}\text { Residential elderly care } \\
\text { home }\end{array}$ & $25(12)$ & $22(36)$ & 142 (79) & $189(42)$ \\
\hline Of which PCU & $13(6)$ & $4(7)$ & $15(8)$ & $32(7)$ \\
\hline Hospice & $4 I(19)$ & $3(5)$ & $0(0)$ & $44(10)$ \\
\hline Other & $2(1)$ & $3(5)$ & $5(3)$ & $10(2)$ \\
\hline
\end{tabular}

PCU: palliative care unit. 
Hofstede, J.M., Raijmakers, N.J.H., Hoek, L.S. van der, Francke, A.L. Differences in palliative care quality between patients with cancer, patients with organ failure and frail patients: a study based on measurements with the Consumer Quality Index Palliative Care for bereaved relatives. Palliative Medicine: 2016, 30(8), 780-788

Table 3. Quality of palliative care provided to patients with different diseases.

\begin{tabular}{|c|c|c|c|c|}
\hline & \multirow{2}{*}{$\frac{\text { Cancer }(n=215)}{\% \text { Negative experience }}$} & \multirow{2}{*}{$\frac{\text { Organ failure }(n=61)}{\% \text { Negative experience }}$} & \multirow{2}{*}{$\frac{\text { Frailty }(n=180)}{\% \text { Negative experience }}$} & \multirow{2}{*}{$\frac{\text { Total }(n=456)}{\% \text { Negative experience }}$} \\
\hline & & & & \\
\hline \multicolumn{5}{|l|}{ CQI dimensions } \\
\hline Expertise & 6 & $14^{*}$ & 9 & 8 \\
\hline $\begin{array}{l}\text { Care for the psychosocial/ } \\
\text { spiritual well-being of the } \\
\text { patient }\end{array}$ & 6 & 10 & 8 & 7 \\
\hline \multicolumn{5}{|l|}{ CQI individual items } \\
\hline \multicolumn{5}{|l|}{ Did your relative ... } \\
\hline $\begin{array}{l}\ldots \text { have access to a counsellor } \\
\text { for spiritual problems? }\end{array}$ & II & 16 & $21^{*}$ & 15 \\
\hline $\begin{array}{l}\text {... accept his/her approaching } \\
\text { death? }\end{array}$ & 17 & 15 & 8 & 13 \\
\hline $\begin{array}{l}\ldots \text { receive support from } \\
\text { the healthcare professionals } \\
\text { with preparations for saying } \\
\text { goodbye to relatives? }\end{array}$ & 14 & 19 & 12 & 14 \\
\hline ... die peacefully? & 10 & 4 & 5 & 7 \\
\hline $\begin{array}{l}\ldots \text { have the opportunity to be } \\
\text { alone if he/she wanted to be? }\end{array}$ & 8 & 2 & 4 & 6 \\
\hline $\begin{array}{l}\text { General quality rating (scale: } \\
0-10 \text { ) }\end{array}$ & $M(\mathrm{SD})$ & $M(\mathrm{SD})$ & $M(\mathrm{SD})$ & $M(\mathrm{SD})$ \\
\hline $\begin{array}{l}\text { Care provided to patient in } \\
\text { last week of life }\end{array}$ & $8.8(1.3)$ & $8.3(1.6)$ & $8.3(1.7)^{*}$ & $8.5(1.6)$ \\
\hline
\end{tabular}

CQI: Consumer Quality Index.

*Significant difference with cancer group, adjusted for age and gender of the deceased patient and age and perceived health of the bereaved relative.

Table 4. Quality of palliative care provided to relatives of patients with different diseases.

\begin{tabular}{|c|c|c|c|c|}
\hline & Cancer $(n=215)$ & Organ failure $(n=6 I)$ & Frailty $(n=180)$ & Total $(n=456)$ \\
\hline & $\begin{array}{l}\% \text { Negative } \\
\text { experience }\end{array}$ & $\begin{array}{l}\% \text { Negative } \\
\text { experience }\end{array}$ & $\begin{array}{l}\% \text { Negative } \\
\text { experience }\end{array}$ & $\begin{array}{l}\text { \% Negative } \\
\text { experience }\end{array}$ \\
\hline \multicolumn{5}{|l|}{ CQI dimensions } \\
\hline $\begin{array}{l}\text { Information for the relative in the last week } \\
\text { before death }\end{array}$ & 18 & 22 & 17 & 18 \\
\hline $\begin{array}{l}\text { Care for the relative's own psychosocial/ } \\
\text { spiritual well-being }\end{array}$ & 16 & 16 & 13 & 15 \\
\hline Autonomy & 8 & 12 & 7 & 8 \\
\hline Attitude to the relatives & 6 & 5 & 8 & 7 \\
\hline \multicolumn{5}{|l|}{ CQI individual items } \\
\hline $\begin{array}{l}\text { Was there a final conversation or discussion in } \\
\text { which the care and treatment were evaluated? }\end{array}$ & 52 & 60 & 64 & 58 \\
\hline $\begin{array}{l}\text { Were you informed about the possibility of } \\
\text { bereavement care after the death of your } \\
\text { relative? }\end{array}$ & 46 & 50 & $64 *$ & 53 \\
\hline $\begin{array}{l}\text { Did you receive information about the } \\
\text { advantages and disadvantages of various types } \\
\text { of treatment? }\end{array}$ & 15 & 23 & 15 & 16 \\
\hline $\begin{array}{l}\text { Did you know who the contact person was for } \\
\text { the care? }\end{array}$ & 9 & 18 & 10 & II \\
\hline $\begin{array}{l}\text { Did you feel supported by the healthcare } \\
\text { professionals immediately after the death of } \\
\text { your relative? }\end{array}$ & 9 & 6 & 8 & 9 \\
\hline $\begin{array}{l}\text { Did you have the opportunity to be alone with } \\
\text { your relative if you wanted to be? }\end{array}$ & 6 & 3 & 4 & 5 \\
\hline General quality rating (scale: $0-10$ ) & $M(S D)$ & $M(\mathrm{SD})$ & $M(\mathrm{SD})$ & $M(S D)$ \\
\hline $\begin{array}{l}\text { Support of healthcare professionals to relatives } \\
\text { before death of patient }\end{array}$ & $8.4(1.7)$ & $7.9(2.1)$ & $7.9(1.9)^{*}$ & $8.1(1.9)$ \\
\hline $\begin{array}{l}\text { Support of healthcare professionals to relatives } \\
\text { after death of patient }\end{array}$ & $7.8(2.2)$ & $7.4(2.4)$ & $7.5(2.1)$ & $7.7(2.2)$ \\
\hline
\end{tabular}

CQI: Consumer Quality Index.

*Significant difference with cancer group, adjusted for age, gender, educational level and perceived health of the bereaved relative. 
Hofstede, J.M., Raijmakers, N.J.H., Hoek, L.S. van der, Francke, A.L. Differences in palliative care quality between patients with cancer, patients with organ failure and frail patients: a study based on measurements with the Consumer Quality Index Palliative Care for bereaved relatives. Palliative Medicine: 2016, 30(8), 780-788

Table 5. Top three areas for improvement in care and support to patients and relatives as identified by relatives.

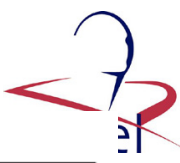

\begin{tabular}{|c|c|c|c|c|}
\hline & Cancer $(n=215)$ & Organ failure $(n=61)$ & Frailty $(n=180)$ & Total $(n=456)$ \\
\hline & $n(\%)$ & $n(\%)$ & $n(\%)$ & $n(\%)$ \\
\hline \multicolumn{5}{|c|}{ Care and support provided to patients } \\
\hline Organisation of care & $21(10)$ & $6(10)$ & $12(7)$ & $39(9)$ \\
\hline Personal attention/support & $8(4)$ & $6(10)$ & $16(9)$ & $30(7)$ \\
\hline Drug management & $13(6)$ & I (2) & $13(7)$ & $27(6)$ \\
\hline \multicolumn{5}{|c|}{ Care and support provided to relatives } \\
\hline Communication to relatives & $14(7)$ & $7(11)$ & $20(\mathrm{II})$ & $41(9)$ \\
\hline Information provision & $14(7)$ & $4(7)$ & $10(6)$ & $28(6)$ \\
\hline Bereavement care & $10(5)$ & $3(5)$ & $8(4)$ & $21(5)$ \\
\hline
\end{tabular}

